\title{
Sustainable Supply Chain Responsiveness Impact of Strategies Competitive Advantage in Jordanian Pharmaceutical Companies
}

\author{
Rawan Thaher Al-tarawneh \\ School of School of Engineering, The University of Jordan, PO box 11942, Amman, Jordan
}

\begin{abstract}
As globalization continues to dissolve the boundaries across the world, the significance of pursuing Strategies competitive advantages in construction is becoming more apparent. This paper applies Porter's diamond framework to identify endogenous sources of competitive advantages of construction enterprises, based on an extensive qualitative research approach. Strategies Competitive advantage helps to determine whether you have a competitive advantage: competitive offers, unique selling proposition (USP), and cost structure. These are important they will attract customers to buy from you and when all your costs are deducted from revenue you will have some profit left over. A competitive advantage involves a lot thing to make competition better however, to seek competition you need to have a strategy. Useful sustainable supply chain responsiveness (SCR) has become a potentially important way of securing strategies competitive advantage since competition is no longer between organizations, but among sustainable supply chains responsiveness. The aim of this research is to find out the effect of sustainable supply chain responsiveness on competitive advantage. Relevant literature is reviewed and synthesized first to develop a conceptual model, followed by research methodology. The results are then presented along with discussion.
\end{abstract}

Keywords: Sustainable Supply Chain Responsiveness and, Strategies Competitive Advantage.

DOI: $10.7176 / \mathrm{EJBM} / 12-26-02$

Publication date:September $30^{\text {th }} 2020$

\section{Introduction}

As a result of the extended supply chains in modern business operations, sustainable supply chain management (SSCM) has started to attract increasing attention from both scholars and practitioners in recent years. The concept of SSCM is usually defined by evaluating the components of its integrated structure. Within its general framework, SSCM includes supply chain management (SCM) and sustainability (Seuring and Müller, 2008). A competitive advantage is an attribute that allows a company to outperform its competitors. Due to this long time, various definitions is presented by scholars for clarify the concept of competitive advantage. Competitive advantage for the organization's ability to provide the products its customers that are they know the more valuable of the competitors provide similar cases (Saloner, Garth, Andrea Shepard and Joel Podolny, 2001). This allows a company to achieve superior margins compared to its competition and generates value for the company and its shareholders. A competitive advantage must be difficult, if not impossible, to duplicate. If it is easily copied or imitated, it is not considered a competitive advantage. Creating responsiveness of sustainable supply chain has been become a source of competitive advantage of the firm (Lau and Hurley, 2001). Many organizations have begun to recognize that SCR is the key to building competitive advantage for their products and services, supply chain responsiveness (SCR) is the centralized management of the flow of goods and services and includes all processes that transform raw materials into final products, Jones, (1998). Sustainable supply chain integration is degree of all the activities within an organization, suppliers, and customers are integrated together (Stevens, 1990; Stock et al., 1998; Stock et al., 2000; Narasimhan and Jayaram, 1998).

Sustainable supply chain integration involves effective communication among all sustainable supply chain members (Turner, 1993). Integration is the term used to describe the various relationships that exist between departments within one company or the relationship between various companies. For example, internally and externally, companies can integrate different activities within the operating company. This activity became apparent (such as product flow, finance, marketing, measurement, etc.) or intangible (such as relationships, information, etc.). Integration not only offers knowledge but also introduces many problems. Managers can design what kind of integration should be focused on, what action should be taken, when various types of overlapping of integration, and what procedures should be followed (Haozhe ,2007). The level of supply chain integration will be able to generate competitive advantage of the firm Mentzer et al (2001). In a differentiation strategy, a company's products or services are differentiated from that of its competitors. This can be done by delivering high-quality products or services to customers or innovating products or services. If a company is able to differentiate successfully, the company would be able to set a premium price on its products or services. Gunasekaran and Yusuf (2002) argued that the firm need to responsiveness and effectiveness. Responsiveness without cost effectiveness is not a real competitive strategy.

Additionally, Sustainable supply chains responsiveness has to be agile and flexible to help the business keep pace with rapid market changes. What is needed is a more strategic and collaborative approach that moves the 
needle from transactional and operational excellence to a strategic partnership with the business. The SCM has been careful from different points of vision in different bodies of literature Croom Romano, Giannakis, (2000), such as purchasing and supply responsiveness, logistics and transportation, operations management, marketing, and management information systems. A competitive advantage distinguishes a company from its competitors. It contributes to higher prices, more customers, and brand loyalty. Establishing such an advantage is one of the most important goals of any company. In today's world, it is essential to business success. Without it, companies will find it difficult to survive. Different theories have offered insights on specific aspects or perspectives of SCM, such as industrial organization and associated transaction cost analysis Ellram, (1990), Rungtusanatham, Salvador, Forza, Choi, (2003), resource-based and resource-dependency theory Cigolini, Cozzi, Perona, (2004).

Therefore, Sustainable supply chain responsiveness natural resources, raw materials, and components into a finished product that is delivered to the end customer. Thatee, (2007) proposed that supply chain responsiveness shall reduce the costs, while leading to competitive advantage for firms on other dimensions as well. In sophisticated supply chain systems, used products may re-enter the supply chain responsiveness at any point where residual value is recyclable, supply chain responsiveness is the assimilation of key business processes from enduser through original suppliers that provides products, services, and information that add value for customers and other stakeholders, (Andreas Wieland, Carl Marcus Wallenburg, 2011). Sustainable supply chain responsiveness is the integration of key business processes from end user through original suppliers that provides products, services, and information that add value for customers and other stakeholders, Competitive advantage examines the economics of a firm's business focusing primarily its ability to generate excess returns on capital and links the business strategy with fundamental finance and capital markets, for a longer period of time (Andreas, et.,al, 2011). Modern supply chains must be able to respond rapidly, effectively and efficiently to changes in the marketplace if they are to endure and create competitive advantage (Adebambo and Adebayo, 2013). The relationship between responsiveness and competitive advantage is illustrated by Sukati et al. (2012), who found that supply chain integration positively impacts on the responsiveness and competitive advantage of the chain as a whole, and that supply chain responsiveness is positively associated with competitive advantage at firm level.

In the end, it is a firm's competitive advantage that allows it to earn excess returns for its shareholders. Without a competitive advantage, a firm has limited economic reason to exist-- its competitive advantage is its reason of life. Creating a sustainable competitive advantage may be the most important goal of any organisation and may be the most important single attribute on which each firm must place its most focus (Lambert, Douglas, Martha, Cooper and Janus, Pagh, 1998).

The strategic process is a required step in integrating the firm with other members of the supply chain responsiveness, and it is at the operational level that the day-to-day activities take placing (Lambert, 2008). This research aims to fulfilling the gap of the literature on the impact of supply chain responsiveness by empirically testing of on competitive advantage. However, due to size limitations and time constraints, only five of the processes and their impacts on competitive advantage fully examined in this research: supplier relationship management.

\section{Research Framework}

This study investigates the competitive advantage through supply chain responsiveness. Based on the figure 1, researchers proposed that supply chain responsiveness that consists of operation system responsiveness (OSR), logistic process responsiveness (LPR) and supply network responsiveness (SNR) are positive related to competitive advantage. Therefore, a conceptual framework for the present research was developed based on the studies conducted previously. Therefore, a conceptual framework for the present research was developed based on the studies conducted previously the Supply chain responsiveness (Kariuki and Kilika, 2017), and competitive advantage concept were based on (Bratic, 2011) studies.

Hence, the following hypotheses will be tested:

H0.1: Sustainable supply chain responsiveness are positively related to competitive advantage in Jordanian pharmaceutical companies.

H1a: Operation system responsiveness is positively related to competitive advantage in Jordanian pharmaceutical companies.

$\mathrm{H} 1 \mathrm{~b}$ : Logistic process responsiveness is positively related to competitive advantage in Jordanian pharmaceutical companies.

H1c: Supply network responsiveness is positively related to competitive advantage in Jordanian pharmaceutical companies. 


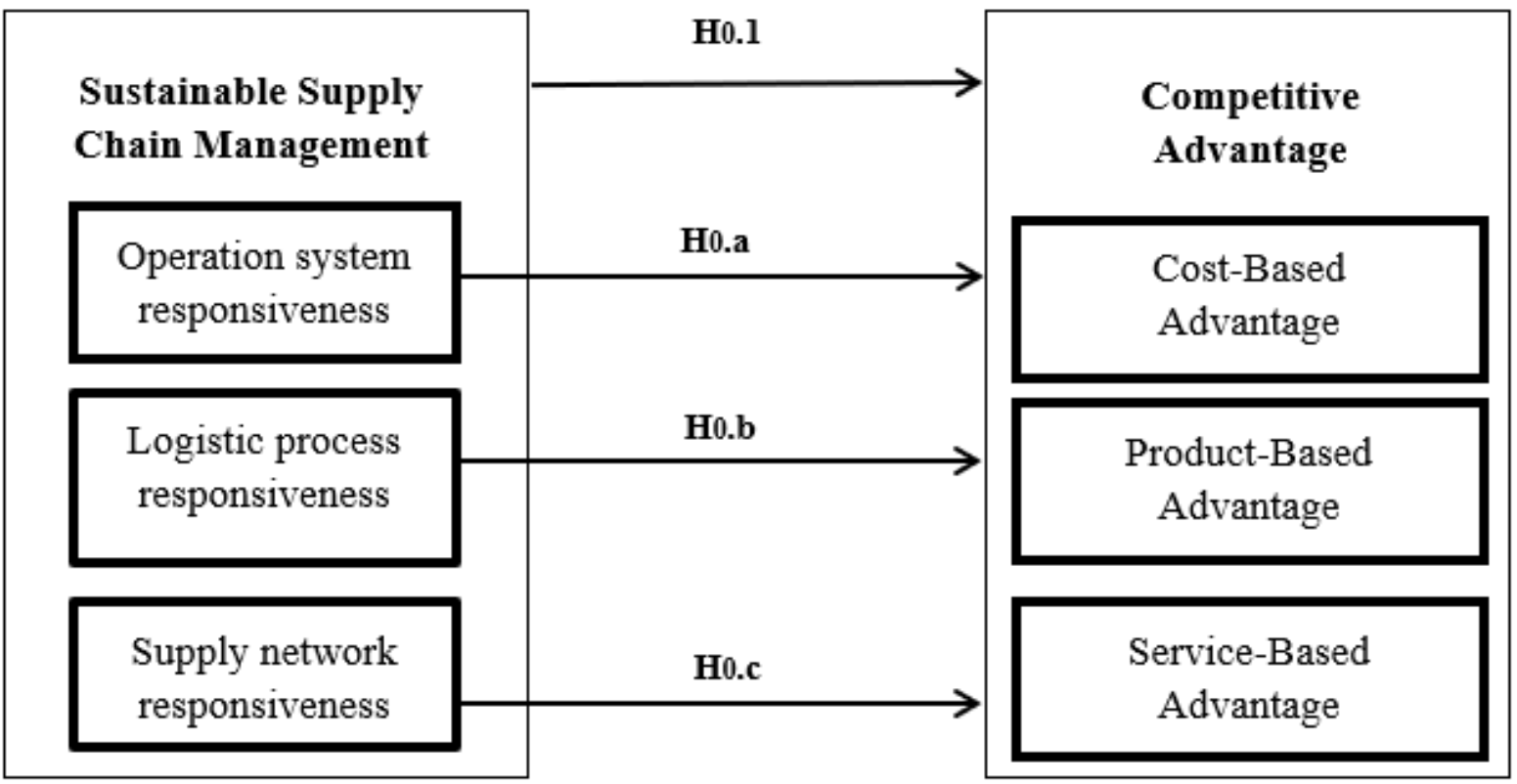

Figure 1. Research Framework

\section{Previous Research}

\subsection{Strategies Competitive Advantage}

Competitive advantage emerges from the creation of superior competencies that are leveraged to create customer value and achieve cost and/or differentiation advantages, 46 resulting in market share and profitability performance (Barney, 1991; Day \& Wensley, 1988). Sustaining competitive advantage requires that firms set up barriers that make imitation difficult through continual investment to improve the advantage, making this a long-run cyclical process (Day \& Wensley, 1988). Porter's approach to competitive advantage centers on a firm's ability to be a low cost producer in its industry, or to be unique in its industry in some aspects that are popularly valued by customers (Porter, 1991). Competitive advantage define as 'a product or service that an organization's customers value more highly than similar offerings from its competitors' (in other words, you have something useful. Competitive advantages are typically temporary as competitors often seek ways to duplicate the competitive advantage (Baltzan \& Phillips 2010).

Strategies Competitive Advantage (SCA) Competitive advantage refers to firms' capability to achieve the greater performance than their competitors (Porter, 1998). In highly dynamic environments, firms need the experience based adaptation to create a competitive advantage (Schilke, 2014). When the complex market environment changes rapidly and competitive advantages are characteristically unsustainable, the entrepreneurial resource is acknowledged as a useful construct to understand the capability of firms to achieve great performance trajectories while others fail (Covin and Lumpkin, 2011).

Competitive Advantage has become one of the important goals of SMEs across the globe (Papula and Volná, 2013). The concept of competitive advantage received wide significance when Porter and Advantage (1985) attempted a definition of competitive advantage as strategies relevant to achieving the long-term market advantage. In furtherance to the inroads of Porter, Barney (1991) attempted a definition of competitive advantage as a longterm benefit resulting from unique value creation processes asynchronously with potential competitors that cannot be easily copied (Jogaratnam, 2017).

Competitive advantage refers to value creation in which a firm pursues high innovation by driving market competition (Kuncoro and Suriani, 2018). A competitive advantage is a constant pursuit of enterprises, because being in a privileged position, presenting unique features of services and/or products, raises and maintains this position in the industrial sector, considering the enterprise's relationships with other peers (Ptsano, 2003). A sustainable competitive advantage emerges as an important factor in the perception of goods and services value, which should be considered as elements of competitive advantage. Because of the importance of Sustainable Competitive Advantage (SCA) to the long-term success of firms, the existing literature addresses its content as well as its sources, and the different types of strategies that may help companies achieve SCA (KIM et al., 2012). However, in the context of value creation, the most common definition of competitive advantage in the field of competitive strategy can be seen in terms of revenues increase over expenses (Kariuki and Kilika, 2017). Rumelt, (2003) on his part sees the competitive advantage as the retention of earnings higher than normal. Competitive advantage is also viewed by (Besanko, Drawnove and Shamley, 2000), as gaining a higher economic profit than 
the average rate of profit in the industry. Competitive advantage is not only determined by better performance than competitors, but how to create superior value for customers (Rungwitoo, 2012). Competitive advantage is the result of the value created by the company for consumers. Consumers will pay fees from superior value/profit/value because prices are lower than competitors (Mohebi \& Farzollahzade, 2014).

The literature shows that there is evidence of differences in the results of competitive advantage when considering the size of the companies, based on the premise that larger companies have a more complex structure, which supports the development of competitive advantages, such as the innovativeness. The variable size of the company can be observed in studies of Traill and Meulenberg (2002), Avermaete et al. (2004) and Triguero, Córcoles and Cuerva (2013).

Competitive advantage refers to a firm's advantages over rival firms that help it to increase its sales (Solnet and Hood, 2008; Brown et al., 2015). In this respect, the firm needs to find the right strategy to confront the challenges faced by its industry. Competitive advantage grows out of ongoing improvement and innovation. Worrying about protecting today's secrets is less important than creating tomorrow's. In his recent study, Porter (2001) reemphasized the importance of analyzing the five competitive forces in developing strategies for competitive advantage: "Although some have argued that today's rapid pace of technological change makes industry analysis less valuable, the opposite is true.

\subsection{Sustainability Supply Chain Responsiveness}

Sustainability strategies competitive advantage (SSCM) can also be considered as the integration of corporate sustainability into SCM whereby the key dimensions of corporate sustainability are combined with SCM characteristics (Ahi and Searcy, 2013). The UN defines sustainability as "meeting the needs of the present without compromising the ability of future generations to meet their own needs" (Cabral et al., 2011). As Baud-lavigne et al. (2012) explained, there was a growing focus on the ways in which human and economic activities have the potential to adversely impact the long-term sustainability of the planet. This responsiveness to demand is satisfied through the adoption of supply chain strategies like just-in-time sourcing (MacCarthy and Jayarathne, 2010) and agile SCM (Bruce et al., 2004). However, in order to become and stay responsive, various ethical (Banres and LeaGreenwood, 2006), employment (De Brito et al., 2008) and environmental issues (Saicheua et al., 2012) are being disregarded, which is creating an unsustainable sectoral structure.

A supply chain that emphasizes responsiveness requires organizations to have flexibility at all echelons of the supply chain (Hopp et al., 2010). Moreover, such supply chains seek flexibility from both long- and short-term perspectives. The former means developing a supply base capable of adapting to structural changes in manufacturing technology, processes, and demand (Lee, 2004). The latter means having suppliers with the ability to meet short-term changes in demand (Gosling et al., 2010). Clarity regarding the need for supply chain responsiveness can also be an important factor in tracking organizational efforts to achieve long- and short-run flexibility (Swafford et al., 2006).

A flexible supply base provides a smooth flow of supplies that reduces the overstocking or under stocking of inventory (Tang and Tomlin, 2008). It can help firms reduce safety stock, lead times, and the need for safety production capacity (Hopp et al., 2010, Yusuf et al., 2003). Supply chain collaboration influences supply chain sustainability through its effect on knowledge transfer and problem-solving associated with supply chain members $[58,59]$. For instance, codes of conduct are used to establish principles in supply chains and require communication to enforce those standards throughout the supply chain (Mamic, 2005, Spence, 2009).

Sustainability Supply Chain Responsiveness (SSCR) also provides a major advantage for companies by decreasing operating costs. SCR activities can reduce the cost of purchasing, production and the total supply chain responsiveness. Lowering costs improves a company's financial position by increasing profit and cash flow. Ghosh, Das and Deshpande (2014) offered an integrative framework that incorporates chain responsiveness, process integration, supply chain coordination and performance, but acknowledge that more research is needed to understand and explore the quantitative relationships between these constructs. Danes, Romano and Formentini (2012) argued that in supply networks, both external and internal integration practices have a significant and positive impact on responsiveness.

However, in spite of so many definitions, we found a simple definition which defines responsive supply chain as the ability of a supply chain to respond quickly to changes in demand, in terms of both volume and mix of products (Christopher, 2000; Holweg, 2005). You and Grossmann (2008) tried to analyze the responsive supply chains under uncertainty using a quantitative model. In our paper we have attempted to extend the work using robust optimization. Thus, responsiveness refers to how fast supply chains can respond to customer demands (Reichhart \& Holweg, 2007). Furthermore, the responsiveness can be different at different nodes within a supply chain, i.e. the responsiveness can increase or decrease depending on where a product or service is located within a supply network (Reichhart \& Holweg, 2007).

Simchi-Levi and Kaminsky (2000) define supply chain responsiveness as "the integration of key business processes among a network of interdependent suppliers, manufacturers, distribution centers, and retailers in order 
to improve the flow of goods, services, and information from original suppliers to final customers, with the objectives of reducing system-wide costs while maintaining required service levels". The Council of Supply Chain responsiveness rrofessionals (CSCM) (2004) defines SCM as: encompasses the planning and management of all activities involved in sourcing and procurement, conversion, and all logistics management activities, including coordination and collaboration with suppliers, intermediaries, third-party service providers, and customers". Some previous studies have focused on sustainability in fashion or clothing supply chains (e.g. De Brito et al., 2008; Armstrong and LeHew, 2011; Nagurney and Yu, 2012). Other definitions of supply chain responsiveness are. Though these definitions differ slightly in wording, all communicate the importance of integration, communication and coordination between functions and organizations that will create value for the customer (Gillyard, 2003).

The term of supply chain responsiveness has grown in popularity over the past two decades, with a lot of research done on the topic (Ashish, 2007). One of the most important factors stimulating the rise of sustainable practices in fast fashion supply chains has been globalization of both sourcing and distribution. According to MacCarthy and Jayarathne (2010), in the last 30 years, textiles manufacturing has shifted significantly to less developed countries. Attempting to combine sustainability and supply chain management goals a more explicit definition has been the following: sustainable supply chain responsiveness (SSCR) is the management of material, information and capital flows as well as cooperation among companies along the supply chain while taking goals from all three dimensions of sustainable development, i.e., economic, environmental and social, into account which are derived from customer and stakeholder requirements (Seuring and Müller, 2008).

Yi, Ngai and Moon (2011) asserted that supply chain responsiveness is best raised by reducing uncertainties and improving supply chain flexibility. The authors identify four types of flexibility strategy (laggard, conservative, agile and aggressive) that are adopted by SC participants in response to environmental uncertainties, and proposed a theoretical framework to assist managers in properly diagnosing and deploying these strategies. Singh and Sharma (2013), meanwhile, employed the analytical network process approach to decide where companies' priorities should lie in terms of flexibility. Tan, Kannan, Handfield and Ghosh (1999) attempted to link certain supply chain responsiveness processes with firm performance. Managing the supply base found that to have a significant impact on firm growth but not on overall performance. The significance of supply chain responsiveness highlights the need for companies actively manage their supply chain responsiveness to maximize their performance (As Mentzer et al., 2001).

\section{Research Methodology}

\subsection{Survey Instrument}

A survey instrument was developed to collect data to test the hypothesized relationships. The first section of the instrument sought demographic information about respondents and the companies they represented. The respondents were asked to indicate on a Likert scale of 1 (strongly disagree) to 5 (strongly agree) on the extent to which supply chain responsiveness, supply chain integration and competitive advantage. Several quantitative statistical technique methods have been used in this study. Narasimhan et al. (2010) provided the basis for items on supply delivery. Items on performance were derived from studies by Brah and Chong (2004) and Qi et al. (2009) (operational performance), Brah et al. (2000), Zu et al. (2008), Kim and Lee (2010) and Kristal et al. (2010) (quality and market performance).

\section{Results and Analysis}

The aim of this research study was to determine if three dimensions of Sustainable Supply Chain Responsiveness processes and Strategies Competitive Advantage. This summarizes the findings of a survey sent out to 120 executive members of the Global Supply Chain Responsiveness. The main hypothesis presented in this research study evaluated using bivariate correlation analysis.

\subsection{Reliability Tests}

To test the reliability of study tool for sample study, Cronbach's Alpha was used and the results revealed a Cronbach's alpha coefficient was (0.882) for all items, and values of $(\alpha)$ range to, which refers the questionnaire is reliable. The values of $(\alpha)$ of the study variables of the study were as in Table (1): 
Table 1. Reliability of Instrument

\begin{tabular}{|c|c|c|}
\hline No. & Field & Alpha. \\
\hline 1 & Operation system responsiveness & 0.895 \\
\hline 2 & Logistic process responsiveness & 0.860 \\
\hline 3 & Supply network responsiveness & 0.841 \\
\hline 4 & Cost-Based Advantage & 0.827 \\
\hline 5 & Product-Based Advantage & 0.826 \\
\hline 6 & Service-Based Advantage & 0.874 \\
\hline 7 & All & 0.882 \\
\hline
\end{tabular}

\subsection{Multicollinearity Test}

To test the existence of multicollinearity phenomena between model variables, Pearson correlation coefficients calculated between independent (predictor) variables, the results of testing multicollinearty between independents variables are explained by correlation matrices and VIF test as following:

Table 2. Link matrix for independent variables

\begin{tabular}{|c|c|c|c|}
\hline Variable & $\begin{array}{c}\text { Operation system } \\
\text { responsiveness }\end{array}$ & $\begin{array}{c}\text { Logistic process } \\
\text { responsiveness }\end{array}$ & $\begin{array}{c}\text { Supply network } \\
\text { responsiveness }\end{array}$ \\
\hline Operation system responsiveness & 1.000 & 1.000 & \\
\hline Logistic process responsiveness & 0.751 & .489 & 1.000 \\
\hline Supply network responsiveness & .562 & $0.751)$ benween \\
\hline
\end{tabular}

Table (2) shows that the highest correlation between the independent variables is $(0.751)$ between the two (Logistic process responsiveness and (Operation system responsiveness)), and this indicates that there is no phenomenon of multiple linear correlation between all the independent variables, as the correlation coefficient values were all less than (0.80), this is an indication that the sample does not suffer from the problem of multiple high linear correlation of independent variables (Guajarti, 2004, 359).

Table 3. Reliability of Instrument

\begin{tabular}{|c|c|c|}
\hline Variable & VIF & Tolerance \\
\hline Operation system responsiveness & 2.657 & 0.258 \\
\hline Logistic process responsiveness & 1.741 & 0.357 \\
\hline Supply network responsiveness & 4.952 & 0.158 \\
\hline
\end{tabular}

Table (3) shows that the values of the coefficient of contrast variation were all greater than the number 1 and less than the number 10, which confirms that there is no problem of multiple linear correlation between all independent study variables (Gujarati, 2004, 253). It is also clear that Tolerance values are greater than (0.05) and this is an indication that there is no high correlation between the independent variables (Gujarati, 2004, 259).

\section{Hypotheses Testing Measurement}

6.1 Multiple Regressions

H01: Sustainable supply chain responsiveness are positively related to competitive advantage in Jordanian pharmaceutical companies.

Table.4. Regression Analysis Sustainable supply chain responsiveness on competitive advantage.

\begin{tabular}{|c|c|c|c|c|c|c|c|c|c|}
\hline \multirow[t]{2}{*}{ Dependent } & \multicolumn{2}{|c|}{$\begin{array}{c}\text { Model } \\
\text { Summery }\end{array}$} & \multicolumn{2}{|c|}{ ANOVA } & \multicolumn{5}{|c|}{ Coefficient } \\
\hline & $\mathrm{R}$ & $\mathrm{r} 2$ & $\mathrm{~F}$ & $\begin{array}{l}\text { Sig } \\
\mathrm{F}^{*}\end{array}$ & Data & B & S.R & $\mathrm{T}$ & Sig $t^{*}$ \\
\hline \multirow{3}{*}{$\begin{array}{l}\text { Competitive } \\
\text { advantage }\end{array}$} & \multirow{3}{*}{.685} & \multirow{3}{*}{0.469} & \multirow{3}{*}{10.425} & \multirow{3}{*}{0.00} & $\begin{array}{l}\text { Operation system } \\
\text { responsiveness }\end{array}$ & 0.088 & 0.049 & 2.110 & 0.011 \\
\hline & & & & & $\begin{array}{l}\text { Logistic process } \\
\text { responsiveness }\end{array}$ & 0.029 & 0.050 & 5.522 & 0.000 \\
\hline & & & & & $\begin{array}{l}\text { Supply network } \\
\text { responsiveness }\end{array}$ & 0.152 & 0.059 & 3.250 & 0.001 \\
\hline
\end{tabular}

The provided results demonstrated that the amount of $(\mathrm{r}=0.685)$ indicates that there is a confident great effect amount among Sustainable supply chain responsiveness and competitive advantage. While $(R 2=0.469)$ that is the relative amount of difference in competitive advantage which can be explained by human resources management practices. As aresult Sustainable supply chain responsiveness explain (31.6\%) of the variability of competitive advantage in Jordanian Medium Enterprises.

Antecedent, the level of $(\mathrm{F})$ was (10.425) at the significant levels (Sig=0.000) and this come to approve the statistically significant of the regression model forecast the outcome variable at the level $(\alpha \leq 0.05)$. As for the table of transactions, it has been shown that the value of B at the distance (Operation system responsiveness) has reached 
$(0.088)$ and that the value of $t$ has $(2.110)$, and at a level of significance $(\mathrm{Sig}=0.011)$, which indicates that the effect of this dimension is significant. The value of B at the (Logistic process responsiveness) dimension was (0.029) and the value of $\mathrm{t}$ at it (5.522), with a significance level $(\mathrm{Sig}=0.000)$, which indicates that the effect of this dimension is significant. The value of B at the (Supply network responsiveness) dimension (0.152) and the value of $\mathrm{t}$ at it (3.2050), with a significance level ( $\mathrm{Sig}=0.001)$, indicating that the effect of this dimension is significant. Based on the above, we reject the first major nihilistic hypothesis and accept the alternative hypothesis that: "Sustainable supply chain responsiveness impact of competitive advantage Jordanian Pharmaceutical Companies.

\subsection{Simple Regression}

H1a: Operation system responsiveness is positively related to competitive advantage in Jordanian pharmaceutical companies.

Table.5. Regression Analysis Operation system responsiveness impact of competitive advantage

\begin{tabular}{|l|c|c|c|c|c|c|c|c|c|}
\hline \multirow{2}{*}{ Dependent } & \multicolumn{2}{|c|}{ Model Summery } & \multicolumn{2}{|c|}{ ANOVA } & \multicolumn{4}{|c|}{ Coefficient } \\
\cline { 2 - 9 } & $\mathrm{R}$ & $\mathrm{r} 2$ & $\mathrm{~F}$ & $\begin{array}{c}\text { Sig } \\
\mathrm{F}^{*}\end{array}$ & Data & $\mathrm{B}$ & $\mathrm{S} . \mathrm{R}$ & $\mathrm{T}$ & $\begin{array}{c}\text { Sig } \\
\mathrm{t}^{*}\end{array}$ \\
\hline $\begin{array}{l}\text { Competitive } \\
\text { advantage }\end{array}$ & .524 & .274 & 23.786 & 0.00 & $\begin{array}{c}\text { Operation system } \\
\text { responsiveness }\end{array}$ & .497 & .102 & 4.877 & .000 \\
\hline
\end{tabular}

The provided results demonstrated that the amount of $(\mathrm{r}=0.524)$ indicates that there is a confident great effect amount among Operation system responsiveness and competitive advantage. While $(\mathrm{R} 2=0.274)$ that is the relative amount of difference in competitive advantage which can be explained by human resources management practices. As aresult Operation system responsiveness explain $(27.4 \%)$ of the variability of competitive advantage in Jordanian Medium Enterprises.

Antecedent, the level of (F) was (23.786) at the significant levels ( $\mathrm{Sig}=0.000)$ and this come to approve the statistically significant of the regression model forecast the outcome variable at the level $(\alpha \leq 0.05)$. B value was $(0.497)$ beside $(\mathrm{T}=4.877)$ at the $(\operatorname{sig}=0.000)$. This approve that the model at $(\alpha \leq 0.05)$ level are statistically significant, and the following hypotheses should be accepted mention that: "Operation system responsiveness effect on competitive advantage in Jordanian pharmaceutical companies".

H1b: Logistic process responsiveness is positively related to competitive advantage in Jordanian pharmaceutical companies.

Table.6. Regression Analysis Logistic process responsiveness on competitive advantage.

\begin{tabular}{|c|c|c|c|c|c|c|c|c|c|}
\hline \multirow{2}{*}{ Dependent } & \multicolumn{2}{|c|}{$\begin{array}{c}\text { Model } \\
\text { Summery }\end{array}$} & \multicolumn{2}{|c|}{ ANOVA } & \multicolumn{5}{|c|}{ Coefficient } \\
\cline { 2 - 9 } & $\mathrm{R}$ & $\mathrm{r} 2$ & $\mathrm{~F}$ & $\begin{array}{c}\text { Sig } \\
\mathrm{F}^{*}\end{array}$ & Data & $\mathrm{B}$ & S.R & $\mathrm{T}$ & Sig t* \\
\hline $\begin{array}{l}\text { Competitive } \\
\text { advantage }\end{array}$ & .604 & .365 & 36.182 & 0.00 & $\begin{array}{c}\text { Logistic process } \\
\text { responsiveness }\end{array}$ & .572 & .095 & 6.015 & 0.000 \\
\hline
\end{tabular}

The provided results demonstrated that the amount of $(\mathrm{r}=0.604)$ indicates that there is a confident great effect amount among Logistic process responsiveness and competitive advantage. While $(\mathrm{R} 2=0.365)$ that is the relative amount of difference in competitive advantage which can be explained by human resources management practices. As a result, Logistic process responsiveness explain $(36.5 \%)$ of the variability of competitive advantage in Jordanian Medium Enterprises.

Antecedent, the level of (F) was (36.182) at the significant levels (Sig=0.000) and this come to approve the statistically significant of the regression model forecast the outcome variable at the level $(\alpha \leq 0.05)$. B value was $(0.572)$ beside $(\mathrm{T}=6.015)$ at the $(\mathrm{sig}=0.000)$. This approve that the model at $(\alpha \leq 0.05)$ level are statistically significant, and the following hypotheses should be accepted mention that: "Logistic process responsiveness impact of competitive advantage in Jordanian pharmaceutical companies"

H1c: Supply network responsiveness is positively related to competitive advantage in Jordanian pharmaceutical companies.

Table.7. Regression Analysis Supply network responsiveness on competitive advantage.

\begin{tabular}{|c|c|c|c|c|c|c|c|c|c|}
\hline \multirow{2}{*}{ Dependent } & \multicolumn{2}{|c|}{$\begin{array}{c}\text { Model } \\
\text { Summery }\end{array}$} & \multicolumn{2}{|c|}{ ANOVA } & \multicolumn{5}{c|}{ Coefficient } \\
\cline { 2 - 9 } & $\mathrm{R}$ & $\mathrm{r} 2$ & $\mathrm{~F}$ & $\begin{array}{c}\text { Sig } \\
\mathrm{F}^{*}\end{array}$ & Data & $\mathrm{B}$ & S.R & $\mathrm{T}$ & Sig t* \\
\hline $\begin{array}{l}\text { Competitive } \\
\text { advantage }\end{array}$ & .495 & .245 & 20.396 & 0.00 & $\begin{array}{c}\text { Supply network } \\
\text { responsiveness }\end{array}$ & .409 & .090 & 4.516 & 0.000 \\
\hline
\end{tabular}

The provided results demonstrated that the amount of $(\mathrm{r}=0.495)$ indicates that there is a confident great effect 
amount among Supply network responsiveness and competitive advantage. While $(\mathrm{R} 2=0.245)$ that is the relative amount of difference in competitive advantage which can be explained by human resources management practices. As aresult Supply network responsiveness explain (24.5\%) of the variability of competitive advantage in Jordanian Medium Enterprises.

Antecedent, the level of (F) was (20.396) at the significant levels (Sig=0.000) and this come to approve the statistically significant of the regression model forecast the outcome variable at the level $(\alpha \leq 0.05)$. B value was $(0.409)$ beside $(\mathrm{T}=4.516)$ at the $(\operatorname{sig}=0.000)$. This approve that the model at $(\alpha \leq 0.05)$ level are statistically significant, and the following hypotheses should be accepted mention that: "Supply network responsiveness impact of competitive advantage in Jordanian pharmaceutical companies".

\section{Conclusion}

While it is reasonable to expect that the alignment of a buyer's a. Sustainable Supply Chain Responsiveness with the Strategies Competitive Advantage, the results provide empirical evidence of the underlying relationships.

\section{References}

Alvarado UY, Kotzab H. (2001). Supply chain responsiveness: the integration of logistics in marketing. Industrial Marketing Management;30 (2):183-98.

Andreas Wieland, Carl Marcus Wallenburg 2011. Supply-Chain-Management in stürmischen Zeiten. Berlin.

Baltzan, p. \& Phillips, A. (2010). Business Driven Technology, 4th edn, McGraw-Hill Irwin, Boston, USA.

Barney, 2002. Gaining and Sustaining Competitive Advantage, 2nd Ed. Prentice Hall, New Jersey.

Childhouse P, Towill DR. (2003). Simplified material flow holds the keyto supplychain integration. OMEGA; 31(1):17-27.

Cigolini R, Cozzi M, Perona M. (2004). A new framework for supplychain management: conceptual model and empirical test. International Journal of Operations and Production Management, 24(1):7-14.

Croom S, Romano P, Giannakis M. (2000). Supplychain management: an analytical framework for critical literature review. European Journal of Purchasing and Supply Management; 6 (1):67-83.

David,J.(2009). Guide to Supply Chain Management: How Getting it Right Boosts Corporate Performance (The Economist Books), Bloomberg Press; 1st edition, ISBN 978-1576603451.

Donlon JP. (1996). Maximizing value in the supply chain. Chief Executive; 117:54-63.

Ellram LM. (1990). The supplier selection decision in strategic partnerships. Journal of Purchasing and Materials and Management; Fall:8-14.

Feldmann M, Müller S. (2003). An incentive scheme for true information providing in supply chains. OMEGA; 31(2):63-73.

Handfield RB, Pannesi RT. (1995). Antecedents of lead-time competitiveness in make-to-order manufacturing firms. International Journal of Production Research; 33 (2).

Jones C. 1998, Moving beyond ERP: making the missing link. Logistics Focus; 6(7):2-7.

Kessler E, Chakrabarti A. 1996. Innovation speed: a conceptual mode of context, antecedents, and outcomes. The Academy of Management Review; 21(4):1143-91.

Koufteros XA, Vonderembse MA, Doll WJ. (1997). Competitive capabilities: measurement and relationships. Proceedings Decision Science Institute; 1067-68.

Lambert, Douglas M., Martha C. Cooper and Janus D. Pagh, (1998). Supply Chain Management: Implementation Issues and Research Opportunities, The International Journal of Logistics Management,9,2.

Rudberg M, Olhager J. (2003). Manufacturing networks and supply chains: an operations strategy perspective. OMEGA; 31(1):29-39.

Rungtusanatham M, Salvador F, Forza C, Choi TY. (2003). Supply chain linkage and operational performance, a resource-based view perspective. International Journal of Operations and Production Management; 23(9):1084-99.

Sadri, Golnaz \& Lees, Brian. (2001). Developing Corporate Culture as a Competitive Advantage, Journal of Management Development,20(10).

Saloner, Garth, Andrea Shepard and Joel Podolny (2001). "Strategic Management”, John Wiley \& Sons, New York.

Tan KC, Kannan VR, Hand field RB. (1998). Supply chain management: supplier performance and firm performance. International Journal of Purchasing and Materials Management; 34 (3).

Tan KC, Lyman SB, Wisner JD. (2002). Supply chain management: a strategic perspective. International Journal of Operations and Production Management; 22(6):614-31.

Vickery, S.K., Jayaram, J., Droge, C., Calantone, R. (2003). The effects of an integrative supply chain strategy on customer service and financial performance: an analysis of direct versus indirect relationships. Journal of Operations Management, 21, 523-539.

Zhang, Y. \& Dilts, D. (2004). Building Adaptive Supply Chain Network: System Dynamics of Supply Chain 
Network Organization Structure. Journal of Information System and e-Business Management.

Zhang, QY. 2001. Technologyinfusion enabled value chain flexibility: a learning and capability-based perspective. Doctoral dissertation, Universityof Toledo, Toledo, $\mathrm{OH}$.

Mamic, I. (2005). Managing Global Supply Chain: The Sports Footwear, Apparel and Retail Sectors. J. Bus. Ethics, 59, 81-100.

Spence, L. (2009). Bourlakis, M. The evolution from corporate social responsibility to supply chain responsibility: The case of Waitrose. Supply Chain Management., 14, 291-302.

Gujarati D, Porter, D, and Sangeetha, G. (2004). Basic Econometrics (5th) edition, USA, New York: The Mc Graw- Hill Gunasekar. 